\title{
Anticancer effect and feasibility study of hyperthermia treatment of pancreatic cancer using magnetic nanoparticles
}

\author{
LUFANG WANG $^{1,2}$, JIAN DONG ${ }^{1}$, WEIWEI OUYANG ${ }^{3}$, XIAOWEN WANG $^{4}$ and JINTIAN TANG ${ }^{4}$ \\ ${ }^{1}$ Department of Biotherapy, The First Affiliated Hospital of Kunming University of Medical Science, Kunming 650032; \\ ${ }^{2}$ Department of Oncology, Anhui Provincial Hospital, Hefei 230001; ${ }^{3}$ Department of Oncology, The Affiliated Hospital, \\ Guiyang Medical University, Guiyang 550004; ${ }^{4}$ Key Laboratory of Particle \& Radiation Imaging, \\ Ministry of Education. Institute of Medical Physics and Engineering, Department of \\ Engineering Physics, Tsinghua University, Beijing 100084, P.R. China
}

Received May 20, 2011; Accepted July 25, 2011

DOI: $10.3892 /$ or.2011.1567

\begin{abstract}
We investigated the effect and feasibility of hyperthermia treatment on subcutaneous pancreatic cancer in female Kunming mice, using a murine pancreatic cancer cell line (MPC-83) established by us and found in this study to originate from epithelial pancreatic acinus. Magnetic fluid (MF) with ferromagnetic particles of about $20 \mathrm{~nm}$ in size was used as a heating mediator. MF was injected into the subcutaneous nodules with subaxillary regions of mice 10 days after tumor transplantation; homogeneous distribution of magnetic nanoparticles in nodules was easily detected by X-ray $24 \mathrm{~h}$ later. Mice were allocated to four groups as follows: no treatment (control); MF injection alone; alternating magnetic field (AMF) irradiation alone; and MF injection and hyperthermia generated by applying AMF (300 kHz, $110 \mathrm{Gs})$. The two hyperthermia-treated subgroup tumors reached central temperatures of 47 and $51^{\circ} \mathrm{C}$, respectively, for $30 \mathrm{~min}$; while rectal temperature in both subgroups remained below $36^{\circ} \mathrm{C}$. Tumor growth was inhibited and survival significantly prolonged in the hyperthermia group compared with other groups $(\mathrm{P}<0.05)$. Tumor cells near the $\mathrm{MF}$ in the hyperthermia group apoptosed or necrosed immediately after hyperthermia. By day 14, there were no subcutaneous nodules; and residual magnetic nanoparticles were ingested by phagocytes. Nuclear
\end{abstract}

Correspondence to: Dr Jian Dong, Department of Biotherapy, The First Affiliated Hospital of Kunming University of Medical Science, Kunming 650032, P.R. China

E-mail: dongjian18@yahoo.com

Dr Jintian Tang, Key Laboratory of Particle \& Radiation Imaging, Ministry of Education. Institute of Medical Physics and Engineering, Department of Engineering Physics, Tsinghua University, Beijing 100084, P.R. China

E-mail: tangjt@mail.tsinghua.edu.cn

Key words: mouse pancreatic cancer cell line, magnetic nanoparticles, hyperthermia, apoptosis, necrosis proliferating cell nuclear antigen (PCNA) decreased in hyperthermia group tumor cells compared to the other groups; cytoplasmic heat shock protein 70 (HSP 70) was conspicuously higher immediately after hyperthermia $(\mathrm{P}<0.05)$. This technique had therapeutic potential and provided a new idea in the treatment of pancreatic cancer.

\section{Introduction}

Pancreatic cancer generally has a poor prognosis. Patients with pancreatic cancer usually have no obvious symptoms in early stages, which usually leads to a poor outcome despite surgery, chemotherapy and radiotherapy (1).

Magnetic nanoparticles have been used to generate heat in an AMF by Brownian and Néel relaxation processes $(2,3)$. This technology has been applied to in vitro experiments (4-6) and animal models of breast cancer, malignant glioma, prostate cancer, malignant melanoma and lymphoma (7-16), as well as clinical trials for prostate cancer and brain tumors (17-20). However, research of this technique in pancreatic cancer has not been reported.

The theory of hyperthermic cancer therapy is based on the greater heat sensitivity of tumor cells than that of healthy cells (21-24). However, traditional heating temperature had achieved non-ideal therapeutic effect; in fact, some researchers had reported that traditional methods promoted the growth of tumor cells (25-28). Nevertheless, in the present study, we have found a novel and potentially useful technique in applying magnetic fluid hyperthermia (MFH) on mouse pancreatic cancer models using a unique mouse pancreatic cancer cell line (MPC-83), established by us in 1983.

In 1983, we found that a male Kunming mouse had spontaneously developed pancreatic cancer. After homologous subcutaneous transplantation, the growth rate of the transplanted neoplasm and resuscitation rate from liquid nitrogen cryopreservation were both $100 \%$. In 1984, it was designated as MPC-83, a unique murine pancreatic cancer cell line. In this study, it was further characterized as an epithelial line originating from a mouse pancreatic acinus. 


\section{Materials and methods}

Cell line and its identification. The MPC-83 cell line was provided free by The First Affiliated Hospital of Kunming University of Medical Science. It was cultured in RPMI-1640 Medium (Gibco, USA) supplemented with $15 \%$ newborn calf serum and antibiotics $(100 \mathrm{U} / \mathrm{m}$ penicillin $\mathrm{G}$ and $0.1 \mu \mathrm{g} /$ $\mathrm{ml}$ streptomycin). MPC- 83 cells were grown at $37^{\circ} \mathrm{C}$ in an atmosphere containing $5 \% \mathrm{CO}_{2}$. The MPC-83 cell line was identified through morphological observation, chromosome karyotype analysis, immunofluorescence of chymotrypsin and pan-cytokeratin, as well as tumor formation rate. Monoclonal chymotrypsin and pan-cytokeratin antibody were purchased from Santa Cruz Biotechnology, Inc. Immunofluorescence kit SABC-Cy3 was purchased from Wuhan Boster Biotechnology, Ltd. Operating procedures were enforced according to reported methods (29).

Animal model. Ninety-eight female Kunming mice, 4 weeks old, were provided by the Laboratory Animal Center of Chinese Academy of Medical Sciences. To prepare tumor-bearing animals, cell suspensions consisting $\sim 1 \times 10^{7} / \mathrm{ml}$ MPC- 83 in $200 \mu 1$ PBS buffer were injected subcutaneously into the right armpit of the mice. Pancreatic cancer nodules that had grown to about $10 \mathrm{~mm}$ in diameter were used for experiments. Tumor diameters were measured every 5 days. About ten days after implantation of tumor cells, the diameter of pancreatic cancer nodules had grown to $10 \mathrm{~mm}$. All animal studies were carried out according to the guidelines of our university.

Preparation of magnetic fluid (MF). The MF (Anhui Jinke Magnetic Fluid Co., Ltd.) used in this study consists of $\mathrm{Fe}_{3} \mathrm{O}_{4}$ nanoparticles with core diameters of $20 \mathrm{~nm}$ and a concentration of $248 \mathrm{mg} / \mathrm{ml}$ in water. The nanoparticles generate heat in an AMF through Brownian and Néel relaxation processes $(2,3)$.

MF injection and analysis of tissue distribution. MF nodule injection was carried out 10 days after tumor cell transplantation. The injection of $0.2 \mathrm{ml}$ of MF solution (net magnetite, $49.6 \mathrm{mg}$ ) into the nodule was performed using a syringe. To obtain a homogeneous distribution of the magnetic nanoparticles within the target area, injections of some directions from entry point were planned, depending on the volume, localization and the shape of the tumor. To enhance the distribution into the surrounding tumor tissue and to avoid rise of pressure, the injection was applied in intervals of $\sim 1 \mathrm{~min}$. The distribution of magnetite in nodules was evaluated through X-ray. Twenty-four hours after MF injection, 4 mice were sacrificed, and the nodule, heart, liver, spleen, lung and kidney were removed to assess the magnetite accumulation by pathological examination.

Hyperthermia treatment. After the pancreatic cancer nodules had grown to about $10 \mathrm{~mm}$ in diameter, 98 femal Kunming mice were separated into four groups: 22 mice in group I, the control group; 22 mice in group II, which received MF injections only; 18 mice in group III, which received $30 \mathrm{~min}$ of AMF radiation only; and 36 mice in group IV, which received both MF injections and AMF hyperthermia to temperature of about 47 or $51^{\circ} \mathrm{C}$. In group IV, $24 \mathrm{~h}$ after MF was directly injected into their tumors, a magnetic induction apparatus (SP-06B-III, 300 kHz, 110 Gs, 300 A, Shenzhen Shuangping Power Supply Technologies Co., Ltd.) was used to apply an alternation magnetic field to the subaxillary region. Anesthetized mice were placed in the convertor coil with their nodules in the middle. Three thermocouples (IT-18, American Physitemp) were used to measure the temperature of nodule center, $0.5 \mathrm{~cm}$ from the tumor center and rectum, respectively. Tumor-bearing mice were each heated once in an AMF to $\sim 47$ or $51^{\circ} \mathrm{C}$ in the nodule centers for $30 \mathrm{~min}$.

Monitoring tumor growth after hyperthermia. Changes in tumor volume and growth rate were investigated, using the formula: volume $=\left(\mathrm{AxB}^{2} \mathrm{x} \pi\right) / 6$, where $\mathrm{A}$ is length-diameter and $B$ is the short diameter. Survival times in each group were also observed.

Pathological examination and immunohistochemical detection. On the day and 14th day after hyperthermia, 4 mice were sacrificed in each group. Subaxillary nodule, heart, liver, spleen, lung and kidney were examined; specimens were fixed in $10 \%$ neutrally buffered formalin and then embedded in paraffin. Serial specimens were then prepared for histological examination and then subjected to hematoxylin and eosin staining. Sections showing immunohistochemical stained proliferating cell nuclear antigen (PCNA antibody, Beijing Zhongshan Golden Brigade Biotechnology Co., Ltd.) and heat shock protein 70 (HSP 70 antibody, Wuhan Boster Biotechnology, Co., Ltd.) were taken and examined immediately after hyperthermia. Specific procedures of immunohistochemistry and evaluation of the stained sections were performed according to reported methods (30-32).

Statistics. Statistical analysis for treatment of increases in temperature, changes in tumor volume and survival times were done using SPSS 13.0. Kaplan-Meier curves were used to calculate survival rate; survival comparison were analyzed with log-rank tests. Significance levels were set at $\mathrm{P}<0.05$.

\section{Results}

Characterization of MPC-83 cell line. MPC-83 grows adhering to the bottom of its vessel, and displays as an irregular form through inverted microscope observation (Fig. 1a). Fig. 1b shows microvilli from cell surface convex to cavity with large nuclear and abundant ribosomes under transmission electron microscopy (TEM).

Giemsa staining was used to analyze chromosome karyotyping in MPC-83, which had a mouse karyotype with 30-34 pairs of chromosomes, including $20 \%$ with abnormal submedian centromeres (Fig. 1c).

Immunofluorescence localization of pan-cytokeratin (Fig. 1d) and chymotrypsin (Fig. 1e) were used to demonstrate that MPC-83 was an epithelial cell that originated from pancreatic acinus.

Its tumor formation rate is $100 \%$ when cell suspensions consisting of $\sim 1 \times 10^{7} / \mathrm{ml}$ MPC- 83 and injected subcutaneously into Kunming mice. On day 3 after implantation, no nodules were recognized through visual inspection; but on day 10 

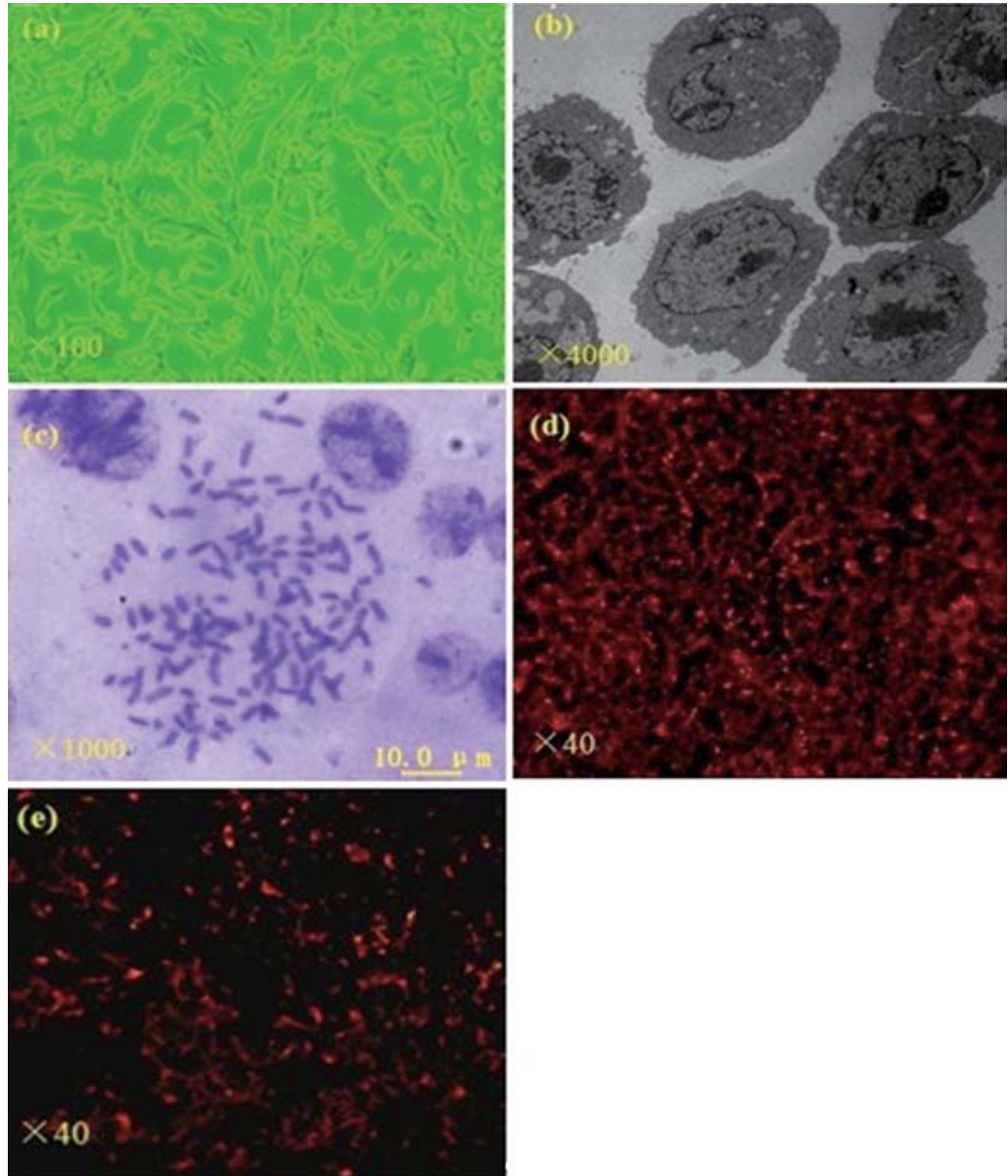

Figure 1. The identification of the MPC-83 cell line. The culture cells under inverted microscope (a) and TEM (b). Karyotype of MPC-83. Giemsa staining was used to analyze somatic chromosomes of MPC-83, which had a mouse karyotype with 30-34 pairs of chromosomes, including $20 \%$ with abnormal submedian centromere (c). Immunofluorescence staining of pan-cytokeratin (d) and chymotrypsin (e).
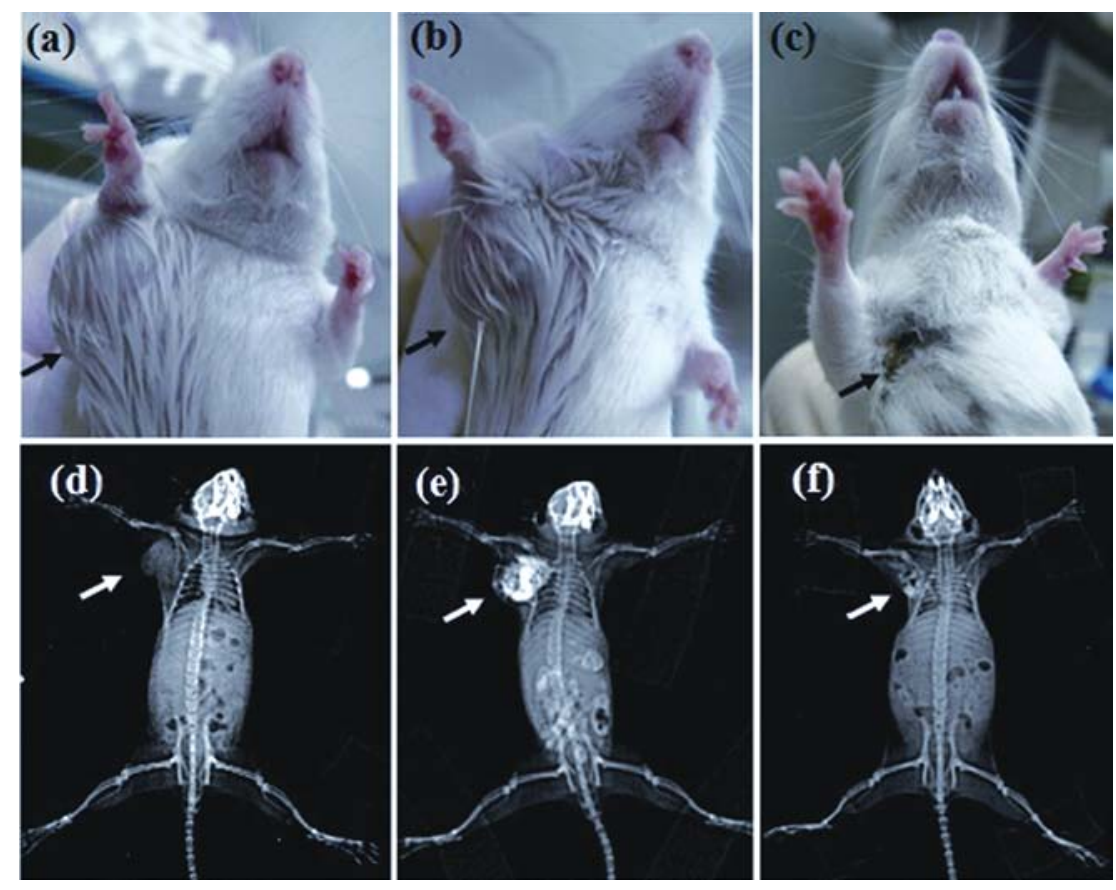

Figure 2. Observation of magnetic nanoparticles pre- and post-MF hyperthermia. (d-f) Represent X-ray image corresponding to (a-c). There is an axillary low density shadow about 10 days after tumor implantation (d). Homogeneous distribution of magnetic nanoparticles in nodules can be easily detected by X-ray $24 \mathrm{~h}$ after MF injection (e). Fourteen days after hyperthermia, there are no subcutaneous nodules; only the MF remains (f). 

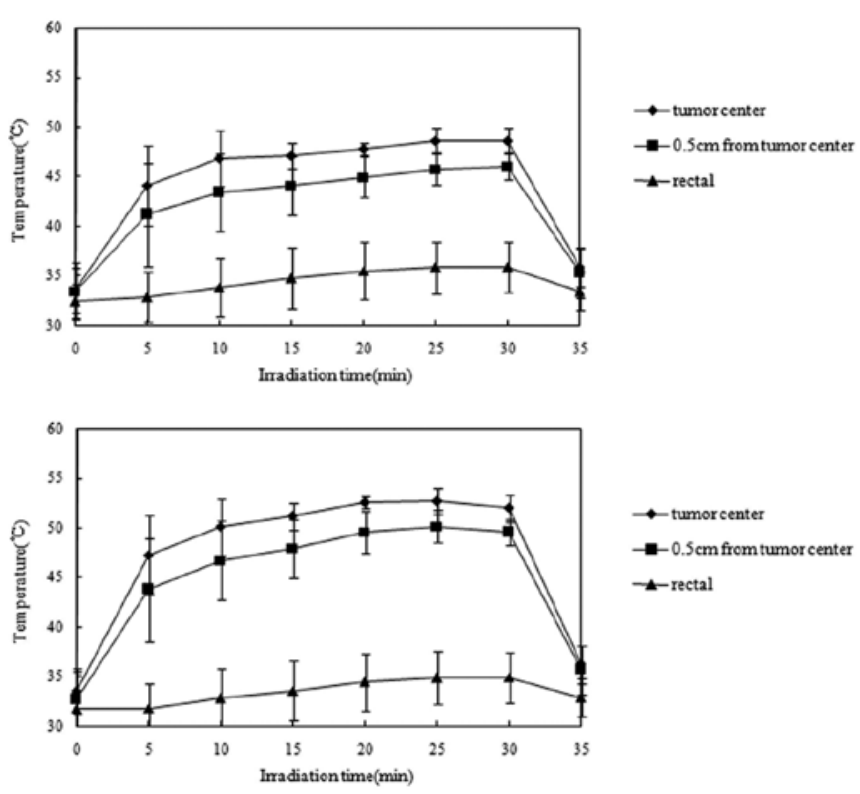

Figure 3. Temperature increases in tumor and rectum.
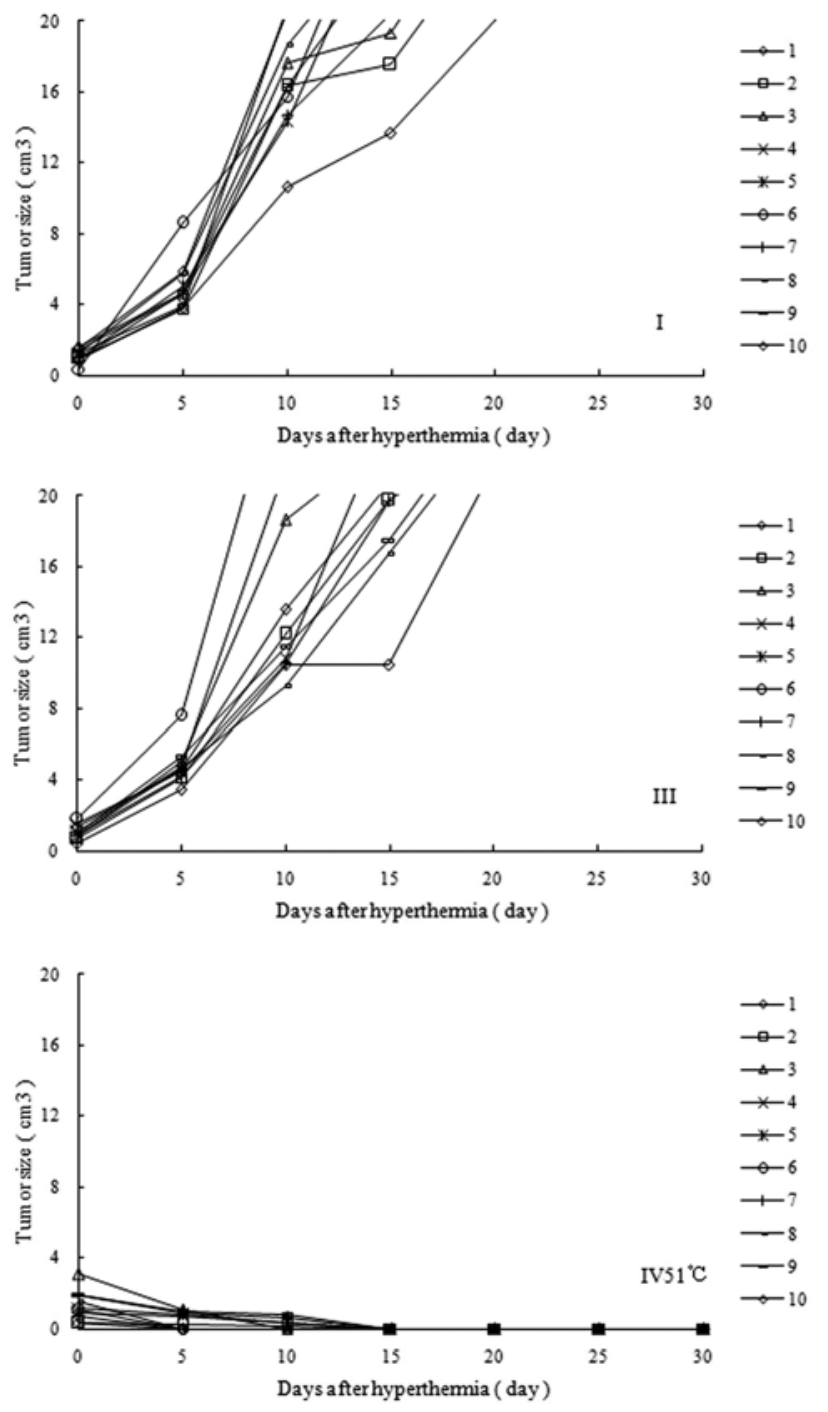

after implantation, subaxillary nodules showed swelling in all samples. Pathological examination found that transplanted tumors presented globular shapes with plentiful blood vessels and center necrosis.

$M F$ injection and analysis of tissue distribution through $X$-ray. As shown in Fig. 2, we could see an axillary low-density shadow about 10 days after tumor implantation (Fig. 2d). The distribution of the implanted MF is measured by X-ray in order to evaluate the uniformity of magnetic nanoparticles in nodules. Homogeneous distribution of magnetic nanoparticles in nodules can be easily detected by X-ray $24 \mathrm{~h}$ after MF injection (Fig. 2e). However, important organ such as heart, liver, spleen, lung and kidney show no magnetite accumulation by pathologic examination.

Heat generation by $M F$ in an AMF. All mice in our study tolerated the hyperthermia treatment without any complications. Fig. 3 shows temperature increases at the tumor center, $0.5 \mathrm{~cm}$ from tumor center and rectum. The AMF was applied for $\sim 30 \mathrm{~min}$. The temperature at the tumor centers reached
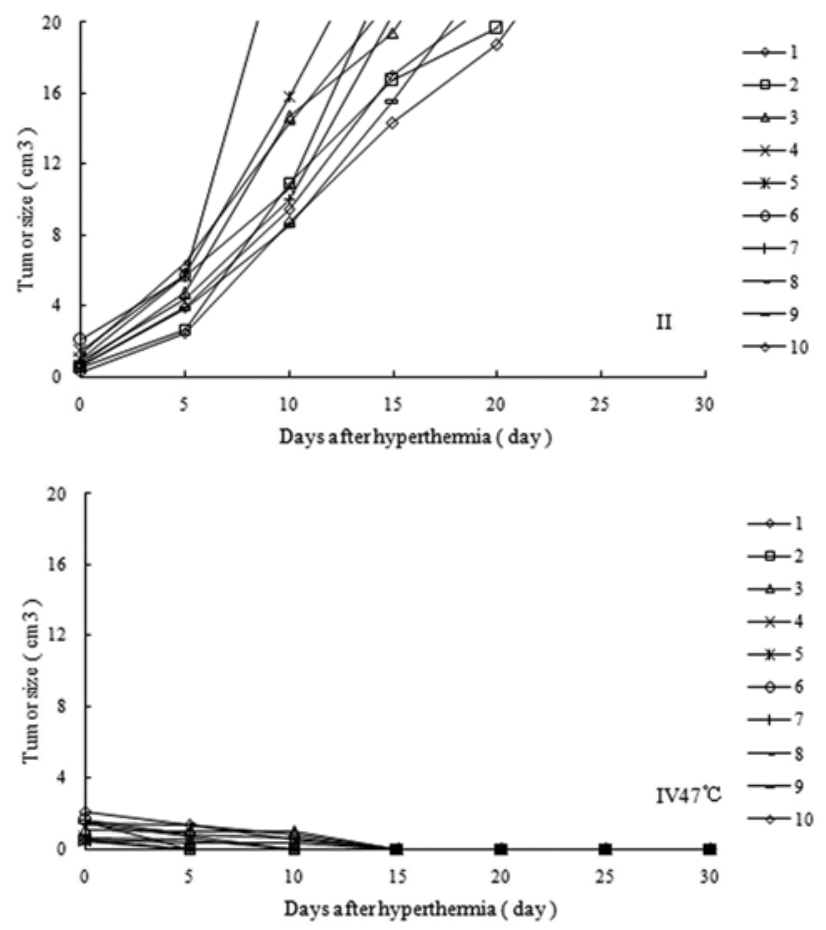

Figure 4. Time course of tumor growth in each group. 


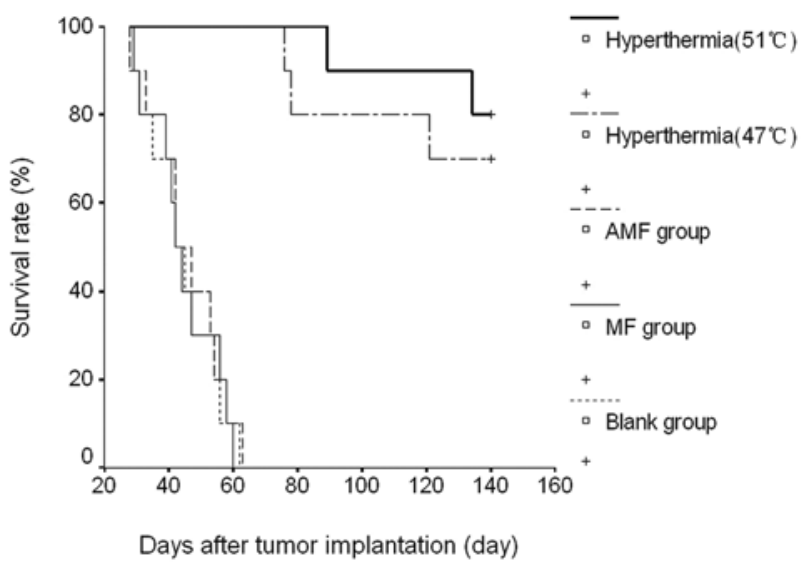

Figure 5. Survival percentage of tumor-bearing mice, observed for a period of 140 days after tumor implantation.

$\sim 47$ or $51^{\circ} \mathrm{C}$ rapidly; it was kept at the same temperature by varying the current intensity in magnetic field. In contrast, rectal temperatures remained below $36^{\circ} \mathrm{C}$. When the $\mathrm{AMF}$ was removed, the temperature at tumor center and $0.5 \mathrm{~cm}$ from tumor center decreased rapidly, reaching body temperature within $5 \mathrm{~min}$. The temperature at the tumor was maintained accurately, with only a small deviation. The temperature difference between the tumor center and $0.5 \mathrm{~cm}$ from tumor center was only about $2^{\circ} \mathrm{C}$. These results suggest that with hyperthermia using MF it is feasible to heat only the tumor and not damage healthy tissues.

Monitoring tumor growth after hyperthermia. Fig. 4 shows the time course of tumor growth in the 10 mice in each group.
After the pancreatic cancer nodules had grown to about $10 \mathrm{~mm}$ in diameter, hyperthermia was carried out. In the three control groups, subcutaneous tumors grew rapidly and their growth were linear. In group IV (hyperthermia at 47 or $51^{\circ} \mathrm{C}$ ), the subcutaneous tumors in 20 mice disappeared within 14 days after hyperthermia with residual magnetic nanoparticles (Fig. 2c). Subcutaneous magnetic nanoparticles can easily be seen through X-ray (Fig. 2f). However, subcutaneous nodules of 3 mice in the $47^{\circ} \mathrm{C}$ group and 2 mice in the $51^{\circ} \mathrm{C}$ group began to relapse within 2 months after hyperthermia. Compared to other groups, tumor growth in the experimental group was remarkably inhibited.

Observation of mouse survival time in each group. The survival percentage of tumor-bearing mice observed for a period of 140 days after tumor implantation is shown in Fig. 5. As shown in Fig. 4, nodules in the three control groups grew rapidly and all the mice were dead by 62,60 and 63 days, respectively. Meanwhile, tumor growth in the experiment group was significantly inhibited; 7 of the 10 mice in the $47^{\circ} \mathrm{C}$ subgroup and 8 of the 10 mice in $51^{\circ} \mathrm{C}$ subgroup had complete cures and were alive 140 days after the hyperthermia treatment. Even though none of the mice were cured completely by the hyperthermia treatment on examination, a significant prolongation of survival was observed compared with the three control groups $(\mathrm{P}<0.05, \mathrm{n}=50)$.

Pathological observation. In Fig. 6a, tumor cells from group I are indicated by their big nucleus and noticeable nucleolus. Twenty-four hours after MF injection, magnetic nanoparticles were distributed among tumor cells (Fig. 6b). In groups II and III, there is no obvious difference of tumor cells compared to group I. Tumor cells around MF in group IV showed apoptosis
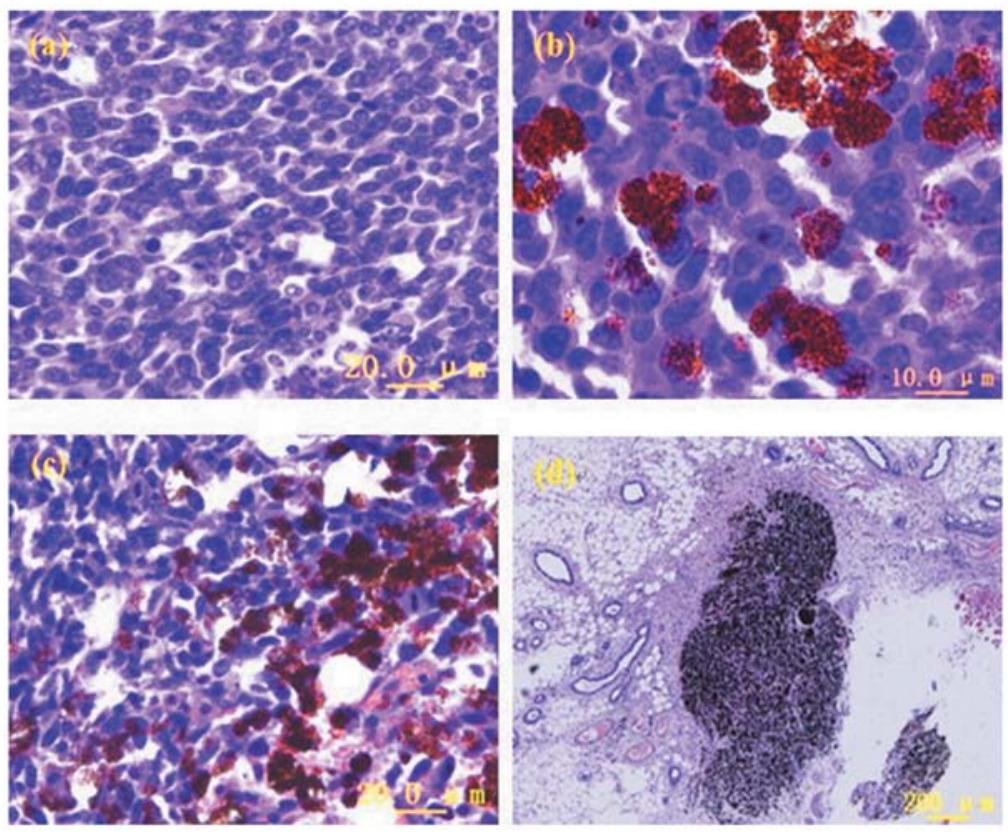

Figure 6. Pathological observation of therapeutic effect using hematoxylin and eosin stain. Light microscopic section of the subcutaneously implanted pancreatic cancer (a, x400). Twenty-four hours after MF injection, magnetic nanoparticles are distributed among tumor cells (b, x1000). Tumor cells around MF in group IV showed apoptosis or necrosis induced immediately by hyperthermia (c, x400). Fourteen days after hyperthermia, there are no subcutaneous tumor cells; only residual magnetic nanoparticles remain $(\mathrm{d}, \mathrm{x} 40)$. 

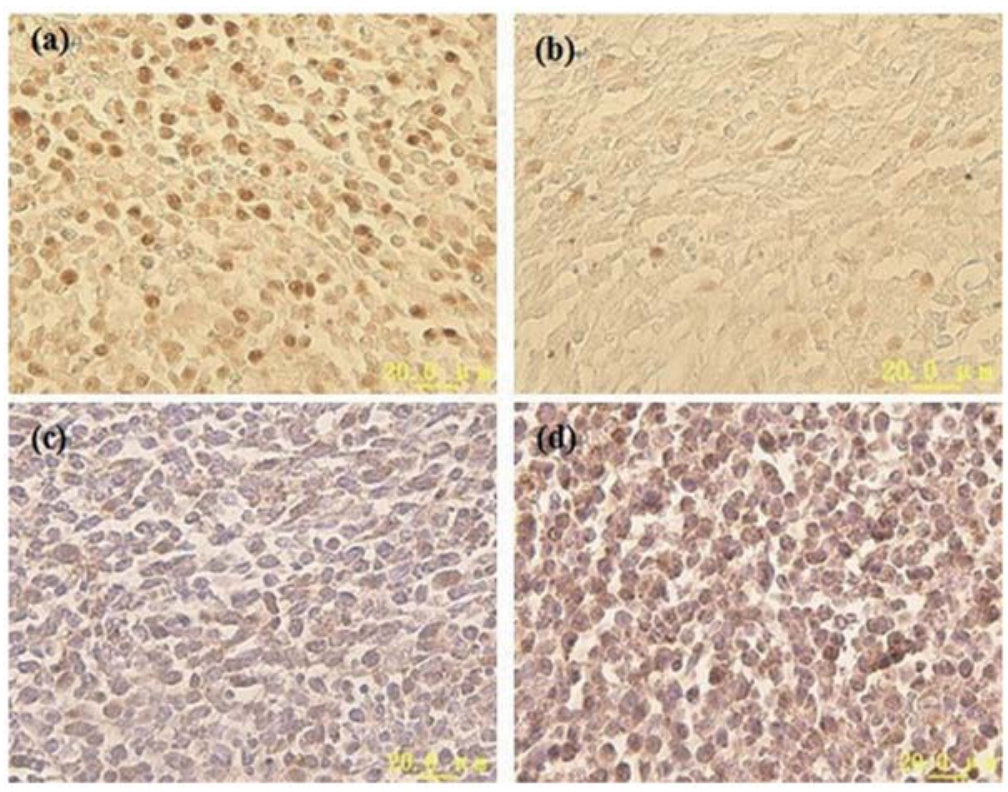

Figure 7. Immunohistochemical detection of PCNA and HSP 70. Light microscopic sections of PCNA (a, b) and HSP 70 (c, d) expression were examined in the tumor tissues of the non-treated mice and those of hyperthermically-treated mice immediately after hyperthermia $\left(47^{\circ} \mathrm{C}\right)$.

or necrosis induced immediately after hyperthermia (Fig. 6c). Fourteen days after hyperthermia, there were no subcutaneous tumor cells, and only residual magnetic nanoparticles ingested by phagocytes (Fig. 6d).

Immunohistochemical detection. Expression of PCNA and HSP 70 were examined in the tumor tissues of the hyperthermically treated mice and the non-treated mice immediately after hyperthermia. The positive expression of PCNA in the nucleus was decreased in experiment group compared to each control group (blank control group, Fig. $7 \mathrm{a} ; 47^{\circ} \mathrm{C}$ group, Fig. 7b). Meanwhile, cytoplasmic HSP 70 in the hyperthermia group $\left(47^{\circ} \mathrm{C}\right.$ group, Fig. $\left.7 \mathrm{~d}\right)$ tumor cells was conspicuously higher than in any of the control groups (blank control group, Fig. 7c). Its expression in tumor tissue heated to $47^{\circ} \mathrm{C}$ was also greater than at $51^{\circ} \mathrm{C}$.

\section{Discussion}

The aim of the present study was to investigate, for the first time, the effect and feasibility of minimally invasive thermotherapy using magnetic nanoparticles on tumor-bearing mice, using our pancreatic cancer cell line MPC- 83 and the novel technique described.

To obtain a sufficiently high temperature completely within the subcutaneous nodule, we injected $0.2 \mathrm{ml}$ of MF solution containing approximately $49.6 \mathrm{mg}$ of magnetite into the nodule. The magnetite concentration $24 \mathrm{~h}$ after injection of the MF showed effective accumulation in nodules for hyperthermia under X-ray examination (Fig. 2e). Deposition of nanoparticles in the subcutaneous nodules was stable for several weeks, making sequential hyperthermia possible without repeated application of MF. No mouse showed adverse reaction after MF injection. Important organ such as heart, liver, spleen, lung and kidney had no magnetite accumulation by pathological examination both $24 \mathrm{~h}$ after MF injection and
14 days after hyperthermia. This is different from the reported (33). Fourteen days after hyperthermia, subcutaneous remnant magnetite can easily be detected through X-ray and pathological examination (Figs. 2c, $\mathrm{f}$ and $6 \mathrm{~d}$ ), which suggests that MF stays securely in place.

Nodular and rectal temperatures were measured invasively during actual hyperthermia treatments in an AMF. Fig. 3 shows that the tumor centers reached 47 or $51^{\circ} \mathrm{C}$ very rapidly, while rectal temperatures remained below $36^{\circ} \mathrm{C}$. The temperature difference between the tumor center and $0.5 \mathrm{~cm}$ from tumor center was only about $2^{\circ} \mathrm{C}$, indicating that the distribution of MF in subcutaneous nodule was stable. These results show that hyperthermia using MF can heat tumor tissue specifically, and that accurate control of the tumor temperature is possible by changing the current intensity in magnetic field.

The efficacy of hyperthermia using magnetite has been demonstrated against several types of tumors in animals. In these cases, our hyperthermia system could specifically generate heat during AMF irradiation at tumor sites that had accumulated magnetite. Moreover, no heat was generated and no histological changes were observed in tissue subjected to AMF irradiation alone without MF. The therapeutic effect of MFH was assessed through monitoring tumor growth, observation of survival time, pathological observation and immunohistochemical detection. We found that the tumor growth rate was decreased significantly, and mouse survival time prolonged, in the hyperthermia group. Pancreatic cancer cells near the MF showed apoptosis or necrosis immediately after hyperthermia through pathological examination. Fourteen days after hyperthermia there were no subcutaneous nodules, although some magnetite remained. MFH offers a promising therapeutic effect.

The expression of PCNA correlates with the late G1 and $\mathrm{S}$ phases of the cell cycle (34-36). The significance of PCNA expression as a marker of tumor growth, invasion, metastasis, or prognosis has been investigated in a wide variety of tumors, such as pituitary adenomas, pancreatic cancer, cervical 
intraepithelial neoplasia, hepatocellular carcinoma, penile squamous and cell carcinoma (37-44). PCNA plays an essential role in nucleic acid metabolism as a component of the replication and repair machinery. The positive expression of PCNA in nucleus was remarkably decreased in the hyperthermia group compared to the three control groups, indicating that it has a relationship with pancreatic cancer growth and survival time. Mice with negative PCNA expression had lower tumor growth rate, longer survival times and better prognosis than those with positive PCNA expression.

Several types of sudden enviromental disruptions, such as high temperature, induce cells to rapidly synthesize a family of proteins known as heat shock proteins (HSPs). HSP 70 plays a major role in the folding and translocation of polypeptides as well as in the assembly and disassembly of oligomeric protein complexes. The expression of HSPs is considered to induce both specific and non-specific antitumor immunity (45). HSP 70 mediated antitumor immunity has been reported to cause a vaccine effect via HSP 70 peptide complexes released from human melanoma cells (46). Tumor-derived HSP 70 immunotherapy is much more effective than IL-2 alone, which significantly inhibits tumor grow and promotes long-term survival (47). In the present study, the expression of HSP 70 in the hyperthermia group was conspicuously higher than in each control group. Its expression in tumor tissue heated to $47^{\circ} \mathrm{C}$ was greater than at $51^{\circ} \mathrm{C}$, suggesting that most of the tumor cells heated to $51^{\circ} \mathrm{C}$ were necrosed by the hyperthermia.

In preclinical studies, we have shown that this novel approach is feasible and effective and may have the potential to improve the unsatisfactory efficacy of conventional therapies in treating pancreatic cancer. As a major advantage of the new technique, we demonstrated that the MF could be distributed within the targeted area, thus enabling the generation of a specific absorbing rating distribution, which may significantly improve the guidance of thermal therapy compared to conventional hyperthermia techniques. The promising results of this study warrant further investigation of hyperthermia using MF with a view to future application in the treatment of pancreatic cancer in humans.

Our study demonstrated that hyperthermia using magnetic nanoparticles might be safely applied in the treatment of pancreatic cancer and that therapeutic temperatures can be achieved efficiently. This is one of the first applications of nanotechnology in pancreatic cancer therapy. It warrants further evaluation and may offer new opportunities in the field of local hyperthermia of tumors. Improved application methods of the nanoparticles, leading to a better coverage of the target volumes, are expected to improve the therapeutic outcome.

\section{Acknowledgements}

This study was supported by 'Fund of Technology-Corporation Between China and Overseas' (2006GH20), National Natural Science Foundation of China (30571779; 10775085), and the Yuyuan Medical Foundation of Tsinghua University (20240000519).

\section{References}

1. Guo X and Cui Z: Current diagnosis and treatment of pancreatic cancer in China. Pancreas 31: 13-22, 2005.
2. Jordan A, Wust P, Fähling H, John W, Hinz A and Felix R: Inductive heating of ferrimagnetic particles and magnetic fluids: physical evaluation of their potential for hyperthermia. Int $\mathbf{J}$ Hyperthermia 9: 51-68, 1993.

3. Mitsumori M, Hiraoka M, Shibata T, et al: Development of intraarterial hyperthermia using a dextran-magnetite complex. Int J Hyperthermia 10: 785-793, 1994.

4. Ito A, Kuga Y, Honda H, Kikkawa H, Horiuchi A, Watanabe $\mathrm{Y}$ and Kobayashi T: Magnetite nanoparticle-loaded anti-HER2 immunoliposomes for combination of antibody therapy with hyperthermia. Cancer Lett 212: 167-175, 2004.

5. Sonvico F, Mornet S, Vasseur S, et al: Folate-conjugated iron oxide nanoparticles for solid tumor targeting as potential specific magnetic hyperthermia mediators: synthesis, physicochemical characterization, and in vitro experiments. Bioconjug Chem 16: 1181-1188, 2005.

6. Tanaka K, Ito A, Kobayashi T, et al: Intratumoral injection of immature dendritic cells enhances antitumor effect of hyperthermia using magnetic nanoparticles. Int J Cancer 116: 624-633, 2005.

7. Hilger I, Hiergeist R, Hergt R, Winnefeld K, Schubert H and Kaiser WA: Thermal ablation of tumors using magnetic nanoparticles: an in vivo feasibility study. Invest Radiol 37: 580-586, 2002.

8. Jordan A, Scholz R, Maier-Hauff K, et al: The effect of thermotherapy using magnetic nanoparticles on rat malignant glioma. J Neurooncol 78: 7-14, 2006.

9. Johannsen A, Jordan A, Scholz R, et al: Evaluation of magnetic fluid hyperthermia in a standard rat model of prostate cancer. $\mathrm{J}$ Endourol 18: 495-500, 2004.

10. Kawai N, Ito A, Nakahara Y, et al: Anticancer effect of hyperthermia on prostate cancer mediated by magnetite cationic liposomes and immune-response induction in transplanted syngeneic rats. Prostate 64: 373-381, 2005.

11. Kawai N, Ito A, Nakahara Y, et al: Complete regression of experimental prostate cancer in nude mice by repeated hyperthermia using magnetite cationic liposomes and a newly developed solenoid containing a ferrite core. Prostate 66: 718-727, 2006.

12. Johannsen M, Thiesen B, Gneveckow U, et al: Thermotherapy using magnetic nanoparticles combined with external radiation in an orthotopic rat model of prostate cancer. Prostate 66: 97-104, 2006.

13. Suzuki M, Shinkai M, Honda H and Kobayashi T: Anticancer effect and immune induction by hyperthermia of malignant melanoma using magnetite cationic liposomes. Melanoma Res 13: 129-135, 2003.

14. Ito A, Tanaka K, Kondo K, et al: Tumor regression by combined immunotherapy and hyperthermia using magnetic nanoparticles in an experimental subcutaneous murine melanoma. Cancer Sci 94: 308-313, 2003.

15. Ito A, Fujioka M, Yoshida T, et al: 4-S-Cysteaminylphenolloaded magnetite cationic liposomes for combination therapy of hyperthermia with chemotherapy against malignant melanoma. Cancer Sci 98: 424-430, 2007.

16. Tanaka K, Ito A, Kobayashi T, et al: Heat immunotherapy using magnetic nanoparticles and dendritic cells for T-lymphoma. J Biosci Bioeng 100: 112-115, 2005.

17. Deger S, Boehmer D, Türk I, Roigas J, Budach V and Loening SA: Interstitial hyperthermia using self-regulating thermoseeds combined with conformal radiation therapy. Eur Urol 42: 147-153, 2002.

18. Johannsen M, Gneveckow U, Eckelt L, et al: Clinical hyperthermia of prostate cancer using magnetic nanoparticles: presentation of a new interstitial technique. Int $\mathbf{J}$ Hyperthermia 21: 637-647, 2005.

19. Wust P, Gneveckow U, Johannsen M, et al: Magnetic nanoparticles for interstitial thermotherapy-feasibility, tolerance and achieved temperatures. Int J Hyperthermia 22: 673-685, 2006.

20. Maier-Hauff K, Rothe R, Scholz R, et al: Intracranial thermotherapy using magnetic nanoparticles combined with external beam radiotherapy: results of a feasibility study on patients with glioblastoma multiforme. J Neurooncol 81: 53-60, 2007.

21. Jordan A, Wust P, Scholz R, et al: Cellular uptake of magnetic fluid particles and their effects on human adenocarcinoma cells exposed to AC magnetic fields in vitro. Int $\mathrm{J}$ Hyperthermia 12: 705-722, 1996.

22. Jordan A, Scholz R, Wust P, et al: Effects of magnetic fluid hyperthermia (MFH) on $\mathrm{C} 3 \mathrm{H}$ mammary carcinoma in vivo. Int $\mathrm{J}$ Hyperthermia 13: 587-605, 1997. 
23. Minamimura $\mathrm{T}$, Sato $\mathrm{H}$, Kasaoka $\mathrm{S}$, et al: Tumor regression by inductive hyperthermia combined with hepatic embolization using dextran magnetite-incorporated microspheres in rats. Int J Oncol 16: 1153-1158, 2000.

24. Moroz P, Jones SK and Gray BN: Tumor response to arterial embolization hyperthermia and direct injection hyperthermia in a rabbit liver tumor model. J Surg Oncol 80: 149-156, 2002.

25. Ito A, Matsuoka F, Honda $\mathrm{H}$ and Kobayashi T: Antitumor effects of combined therapy of recombinant heat shock protein 70 and hyperthermia using magnetic nanoparticles in an experimental subcutaneous murine melanoma. Cancer Immunol Immunother 53: 26-32, 2004.

26. Ito A, Matsuoka F, Honda $\mathrm{H}$ and Kobayashi $\mathrm{T}$ : Heat shock protein 70 gene therapy combined with hyperthermia using magnetic nanoparticles. Cancer Gene Ther 10: 918-925, 2003

27. Ito A, Shinkai M, Honda H, et al: Heat shock protein 70 expression induces antitumor immunity during intracellular hyperthermia using magnetite nanoparticles. Cancer Immunol Immunother 52 : 80-88, 2003

28. Ito A, Shinkai M, Honda H, Wakabayashi T, Yoshida $\mathrm{J}$ and Kobayashi T: Augmentation of MHC class I antigen presentation via heat shock protein expression by hyperthermia. Cancer Immunol Immunother 50: 515-522, 2001.

29. Shimaoka S, Matsushita S, Nitanda T, et al: The role of thymidine phosphorylase expression in the invasiveness of gastric carcinoma. Cancer 88: 2220-2227, 2000.

30. Jimenez RE, Z'graggen K, Hartwig W, Graeme-Cook F, Warshaw AL and Fernandez-del Castillo C: Immunohistochemical characterization of pancreatic tumors induced by dimethylbenzanthracene in rats. Am J Pathol 154: 1223-1229, 1999.

31. Konno S, Takebayashi Y, Aiba M, Akiyama S and Ogawa K: Clinicopathological and prognostic significance of thymidine phosphorylase and proliferating cell nuclear antigen in gastric carcinoma. Cancer Lett 166: 103-111, 2001.

32. Cai ZG, Shi XJ, Gao Y, Wei MJ, Wang CY and Yu GY: Betacatenin expression pattern in primary oral squamous cell carcinoma. Chin Med J (Engl) 121: 1866-1870, 2008.

33. Hamaguchi S, Tohnai I, Ito A, et al: Selective hyperthermia using magnetoliposomes to target cervical lymph node metastasis in a rabbit tongue tumor model. Cancer Sci 94: 834-839, 2003.

34. Celis JE and Celis A: Cell cycle-dependent variations in the distribution of the nuclear protein cyclin proliferating cell nuclear antigen in cultured cells: subdivision of S phase. Proc Natl Acad Sci USA 82: 3262-3266, 1985.

35. Morris GF and Mathews MB: Regulation of proliferating cell nuclear antigen during the cell-cycle. J Biol Chem 264 13856-13864, 1989.
36. Fujise K, Zhang D, Liu J and Yeh ET: Regulation of apoptosis and cell cycle progression by MCL1-differential role of proliferating cell nuclear antigen. J Biol Chem 275: 39458-39465, 2000.

37. Pawlikowski M, Gruszka A, Kurnatowska I, Winczyk K, KunertRadek J and Radek A: Proliferating cell nuclear antigen (PCNA) expression in pituitary adenomas: relationship to the endocrine phenotype of adenoma. Folia Histochem Cytobiol 44: 37-41, 2006.

38. Mäkinen K, Loimas S, Hakala T and Eskelinen M: Tumour suppressor protein (p53), apoptosis inhibiting protein (Bcl-2) and proliferating cell nuclear antigen (PCNA) expressions in a rat pancreatic tumour model. Anticancer Res 27: 23-26, 2007.

39. Branca M, Ciotti M, Giorgi C, et al: Up-regulation of proliferating cell nuclear antigen (PCNA) is closely associated with high-risk human papillomavirus (HPV) and progression of cervical intraepithelial neoplasia (CIN), but does not predict disease outcome in cervical cancer. Eur J Obstet Gynecol Reprod Biol 130: 223-231, 2007

40. Hosokawa M, Takehara A, Matsuda K, et al: Oncogenic role of KIAA0101 interacting with proliferating cell nuclear antigen in pancreatic cancer. Cancer Res 67: 2568-2576, 2007.

41. Guimarães GC, Leal ML, Campos RS, et al: Do proliferating cell nuclear antigen and MIB-1/Ki-67 have prognostic value in penile squamous cell carcinoma? Urology 70: 137-142, 2007.

42. Lyshchik A, Higashi T, Hara T, et al: Expression of glucose transporter-1, hexokinase-II, proliferating cell nuclear antigen and survival of patients with pancreatic cancer. Cancer Invest 25: 154-162, 2007.

43. Hu TH, Wang CC, Huang CC, et al: Down-regulation of tumor suppressor gene PTEN, overexpression of $\mathrm{p} 53$, plus high proliferating cell nuclear antigen index predict poor patient outcome of hepatocellular carcinoma after resection. Oncol Rep 18: 1417-1426, 2007

44. Tong QS, Jiang GS, Zheng LD, et al: Methyl jasmonate downregulates expression of proliferating cell nuclear antigen and induces apoptasis in human neuroblastoma cell lines. Anticancer Drugs 19: 573-581, 2008.

45. Li D, Li H, Zhang P, et al: Heat shock fusion protein induces both specific and non-specific anti-tumor immunity. Eur J Immunol 36: 1324-1336, 2006.

46. Castelli C, Ciupitu AM, Rini F, Rivoltini L, Mazzocchi A, Kiessling R and Parmiani G: Human heat shock protein 70 peptide complexes specifically activate antimelanoma $\mathrm{T}$ cells. Cancer Res 61: 222-227, 2001.

47. Fu Q, Meng F, Shen X and Guo R: Therapeutic efficacy of tumor-derived heat shock protein 70 immunotherapy combining interleukin-2 on tumor-bearing mice. Chin Med J (Engl) 116: 288-291, 2003 